\title{
Production of identical twins by bisection of blastocysts in the cow
}

\author{
J. P. Ozil \\ I.N.R.A., Station centrale de Physiologie animale, 78350 Jouy-en-Josas, France
}

\begin{abstract}
Summary. Day- 8 embryos were recovered by a non-surgical method from superovulated crossbred heifers. Normal expanded blastocysts with a distinct inner cell mass and a trophoblast were released from the zona pellucida and bisected along a sagittal plane into two 'half' blastocysts. Each 'half' blastocyst was replaced in an empty zona pellucida and cultured for $2 \mathrm{~h}$ in B2 medium. After culture the 'half' blastocysts were directly transferred to recipient heifers via the cervix. From 11 blastocysts, 11 monozygotic 'half' blastocyst pairs were transferred to 11 recipients: 8 recipients became pregnant, 4 carried twins and one delivered a normal calf and an acardiacus amorphus monster consisting of disorganized embryonic tissues. A further 11 'half' blastocysts were transferred as singletons to 11 recipients. Five recipients were apparently pregnant at Day 42. One returned to oestrus at Day 45, 3 were carrying normal fetuses and 1 a pair of normal twin fetuses when slaughtered at Day 128.

It is concluded that even after the first irreversible cellular differentiation which occurs at the blastocyst stage it is still possible to produce identical cattle twins by bisection of the Day- 8 blastocyst.
\end{abstract}

\section{Introduction}

Micromanipulation experiments on cattle embryos have shown that the embryos, in spite of a great reduction in their cell number, are able to develop through early cleavage (Willadsen \& Polge, 1981) and up to blastocyst formation (Ozil, Heyman \& Renard, 1982). The simple bisection of fully compacted late morulae or early blastocysts allows the production of identical twins in routine embryo transplantation procedures in cattle.

However, methods of producing identical twins can only be fully exploited in association with techniques of cryopreservation which would permit transfer of each 'half' of the same embryo at different times.

We have therefore tested the survival of blastocysts bisected on Day 8 , the optimum stage of development for tolerating cryopreservation by current techniques (Renard, Heyman \& Ozil, 1982). We have also examined development rate after the transfer of a monozygotic pair of 'half' blastocysts or of a single 'half' blastocyst into the horn ipsilateral to the corpus luteum.

\section{Materials and Methods}

The donor animals (heifers of mixed origin) had been induced to superovulate by the technique of Elsden, Nelson \& Seidel (1978) (32 mg FSH given i.m. in decreasing doses over 5 days). The cycle of the recipient heifers was synchronized with that of the donor by two injections each of $500 \mu \mathrm{g}$ cloprostenol (Estrumate: I.C.I. Ltd, Macclesfield, U.K.). Embryos were recovered non-surgically 
in phosphate-buffered saline solution (PBS: Whittingham, 1971) at Day 8 after oestrus using the method described by Ozil, Heyman \& Cassou (1980). Embryos were maintained at room temperature in B2 medium (Ménézo, 1976; Api System, La Balme les Grottes, 38390 Montalieu Versieu, France) under an atmosphere of $5 \% \mathrm{CO}_{2}, 5 \% \mathrm{O}_{2}, 90 \% \mathrm{~N}_{2}$. Only embryos showing a distinct inner cell mass (ICM) and a distinct trophoblast within the zona pellucida were used.

An inverted microscope (Nikon TMD 10) was used with 6 pneumatic micromanipulators developed by de Fonbrune (C.I.T. Alcatel, Paris, France). The 6 micromanipulators, 2 with high precision (type A) and 4 simpler models (type B), were arranged so as to control independently and simultaneously 6 microinstruments in the optical field of the microscope (P1. 1, Fig. 1). This micromanipulation system was developed from that used for post-compaction/pre-blastocyst bovine embryos (Ozil et al., 1982). The embryo was held by suction at the tip of a micropipette of $130 \mu \mathrm{m}$ external diameter (Pl. 1, Fig. 2). The zona pellucida was partly cut open in the middle using a pair of glass microneedles (Pl. 1, Fig. 3). During the opening of the zona pellucida the blastocoele was punctured with the two glass microneedles. The trophoblast contracted and the slit in the zona was continued without any further damage to the trophoblast. To show the slit the embryo was then rotated with the microneedles through $90^{\circ}$ to orientate the slit in the zona pellucida in the vertical plane of observation. A glass micropipette, of $30 \mu \mathrm{m}$ external diameter, was passed through the opening of the zona pellucida and the blastocyst expelled from the zona pellucida by a gentle injection of medium (Pl. 1, Figs 4 \& 5). The blastocyst was bisected as closely as possible along its sagittal plane (Pl. 1, Figs 6 \& 7) using a microscalpel made from a surgical scalpel as shown in Textfig. 1. For optimal section of the blastocyst, the microscalpel cutting edge was positioned in the vertical plane to prevent rotation of the embryo at bisection, and horizontally so that the cutting edge was parallel to the bottom of the dish; each embryo was then separated in two 'halves' along the sagittal plane. Each 'half' embryo was placed into an empty zona pellucida (Pl. 1, Figs 8 \& 9). Zonae pellucidae for this purpose were obtained from oocytes taken from cow ovaries collected at the slaughter house. The zonae were opened by the method described above and emptied with a micropipette. These zonae had been stored at $-20^{\circ} \mathrm{C}$ in a phosphate-buffered saline solution containing $20 \%$ fetal calf serum (Willadsen, 1980). 'Half' blastocysts were then incubated at $37^{\circ} \mathrm{C}$ for $2 \mathrm{~h}$ in $\mathrm{B} 2$ medium under an atmosphere of $5 \% \mathrm{CO}_{2}+5 \% \mathrm{O}_{2}+90 \% \mathrm{~N}_{2}$. Re-formation of the blastocoele was observed under a dissecting microscope (Pl. 1, Fig. 10).

\section{PLATE 1}

Method of bisection of cow blastocysts by micromanipulation.

Fig. 1. Six microinstruments are placed in the optical field of an inverted microscope. Two micropipettes controlled by type-B micromanipulators hold the blastocyst and the empty zona pellucida by negative pressure; 2 instruments with a sharp tip in front of the blastocyst are controlled by a type-A micromanipulator. The micropipette on the left and the microscalpel on the right are controlled by a type-B micromanipulator. This equipment allows the bisection of 6-8 blastocysts per hour.

Figs 2 \& 3. The two sharp microneedles cut the zona pellucida over as short a distance as possible along the middle. The blastocyst is subsequently rotated through $90^{\circ}$ with the two microneedles to show the slit.

Figs $4 \& 5$. The micropipette is introduced through the slit inside the zona while a small volume of medium is injected to expel the embryo.

Figs $6 \& 7$. Bisection of the blastocyst is achieved using the microscalpel along the sagittal plane.

Figs 8 \& 9. Using the suction of the micropipette each 'half' embryo is put back into an empty zona pellucida.

Fig. 10. 'Half' embryos are then incubated at $37^{\circ} \mathrm{C}$ for $2 \mathrm{~h}$. They reconstitute their blastocoele and it is possible to distinguish again the inner cell mass in each 'half' blastocyst. The cells destroyed during the bisection adhere to the outer surface of the 'half' blastocyst. 


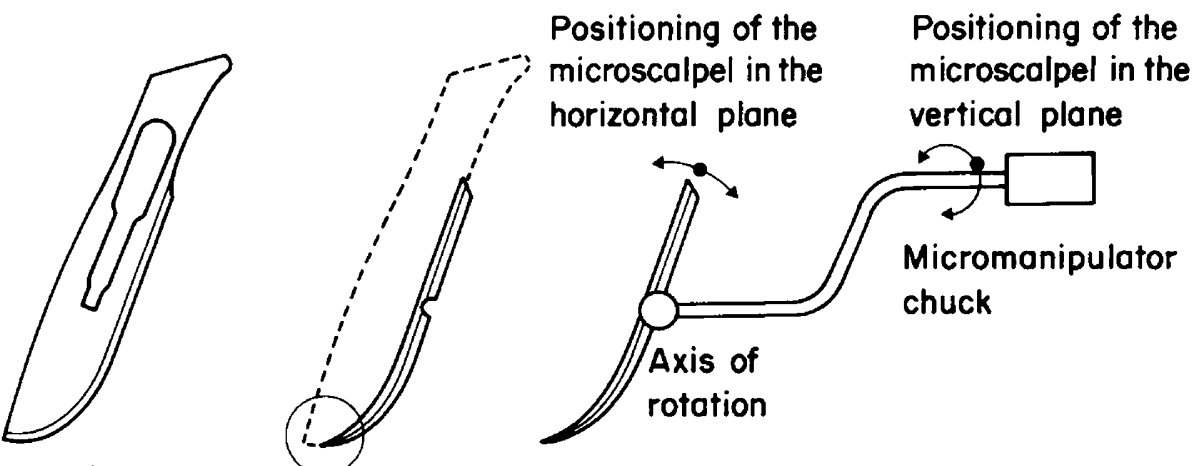

Surgical scalpel blade before machining (Swann-Morton $\mathrm{N}^{\circ} 21$ )

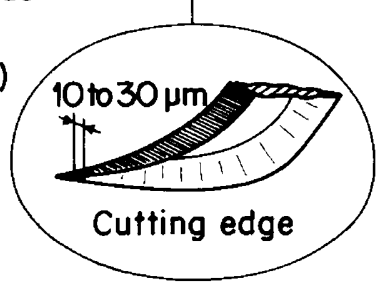

\author{
Microscalpel blade after machining \\ and mounted on its adjustable support
}

Text-fig. 1. Diagram to show the preparation and mounting of the microscalpel.

The viability of 'half' blastocysts was tested by transferring them directly via the cervix to Day8 recipients. The 'half' blastocysts were put into a straw in $0.02 \mathrm{ml} \mathrm{B} 2$ medium and deposited using a Cassou gun about $10 \mathrm{~cm}$ inside the uterine horn ipsilateral to the corpus luteum. Two groups of 11 recipients in each received respectively 11 pairs of 'half' blastocysts derived from 11 blastocysts (Group 1) and 11 'half' blastocysts from further 11 blastocysts (Group 2).

Each recipient was checked twice daily for return to oestrus, and an early pregnancy diagnosis using plasma progesterone assay was performed on Day 21. Twin pregnancy was confirmed by ultrasonic echography between Day 31 and Day 86 (Chupin \& Procureur, 1983). Recipients recorded as carrying only one fetus were slaughtered between Day 45 and Day 135 and those recorded as carrying twins were allowed to go to term. To establish the identity of the twins born, blood typing was done according to the technique described by Grosclaude, Guérin \& Houlier (1979).

\title{
Results
}

After $2 \mathrm{~h}$ of culture in vitro, 16/22 'half' blastocysts in Group 1, and 10/11 'half' blastocysts in Group 2 had re-expanded to form normally organized blastocysts, an overall re-expansion rate of $26 / 33$ $(79 \%)$ (Table 1$)$.

In Group 1, 8 of the 11 recipients which had each received a pair of 'half' blastocysts were pregnant at Day 42. Four were recorded by ultrasonic echography as carrying twins and were allowed to go to term; 2 delivered pairs of twins (Pl. 2, Fig. 11). Analysis of the blood group for each couple of twins showed that the blood type formulae were identical. A third recipient delivered a single normal calf and the 4th delivered a normal calf and a globular mass of tissue (Pl. 2, Fig. 12), $10 \mathrm{~cm}$ in diameter and $220 \mathrm{~g}$ in weight. Such a formless mass has been called a fetal monster of the acardiacus amorphus type (Dunn, Lein \& Kenney, 1967; Eldrige, 1980). Dissection revealed that it included several tissue types; digestive tract, blood, glandular tissue and fat, but no bone or cartilage. The mass was surrounded by skin covered with hair. Four other recipients recorded as carrying 1 fetus were slaughtered between Day 51 and Day 91 of pregnancy. Two were carrying a pair of normal twin fetuses and 2 had only one live fetus. 
Table 1. Viability of 'half' blastocysts after twin transfer (Group 1) or single transfer (Group 2)

\begin{tabular}{|c|c|c|c|c|}
\hline & \multicolumn{2}{|c|}{ Group 1} & \multicolumn{2}{|c|}{ Group 2} \\
\hline & No. & $(\%)$ & No. & $(\%)$ \\
\hline Blastocysts bisected & 11 & & 11 & \\
\hline 'Half' blastocysts produced & 22 & & $11^{*}$ & \\
\hline \multicolumn{5}{|l|}{ 'Half' blastocysts showing expanded } \\
\hline blastocoeles after $2 \mathrm{~h}$ in culture & 16 & $(72 \cdot 7)$ & 10 & $(90.9)$ \\
\hline Recipients & 11 & & 11 & \\
\hline Recipients pregnant at Day 45 & 8 & $(72 \cdot 7)$ & 4 & $(36 \cdot 3)$ \\
\hline Twin pregnancies & 4 & $(50 \cdot 0)$ & $1 \dagger$ & \\
\hline Fetuses obtained & 12 & $(109 \cdot 0)$ & 5 & \\
\hline
\end{tabular}

* The other 11 'half' blastocysts were used in another experimental trial.

† One recipient was found to be carrying twins after the transfer of a single 'half' blastocyst.

In Group 2, 5 of the 11 recipients that had each received a single 'half' blastocyst did not return to oestrus at Day 42. One returned to oestrus at Day 45 and 4 which were slaughtered between Day 45 and Day 135 were pregnant. Three were carrying normal fetuses and one a pair of normal live female twin fetuses, the crown-rump and the weight of which were identical ( $32 \mathrm{~cm}$ and $1.4 \mathrm{~kg}$ ).

\section{Discussion}

A preliminary study (Ozil, 1982) showed that the bisection of a Day-8 cow blastocyst cannot be achieved by the method used for the Day-6-Day-7 morulae (Ozil et al., 1982). Because of the development of very strong junctions between the cells by Day 8 (Massip et al., 1981) it is necessary to cut the blastocyst neatly. For this purpose we used an adjustable microscalpel to obtain a clean division of the blastocyst. The large number of 'half' blastocysts that had a reconstituted cavity after $2 \mathrm{~h}$ in culture $(79 \%)$ shows that healing and fluid accumulation in the blastocoele are very rapid. The intercellular adhesion of the trophoblast cells described by Daniel (1963) and the joining edge to edge of the trophoblast layer along each side of the microscalpel during the bisection are responsible for the trophoblast's ability to reconstitute continuity after bisection. Three of the 'half' blastocysts in which the cavity had not reformed before transfer developed to normal fetuses. It might not, therefore, be necessary to test the viability in vitro of the bisected blastocysts before transfer.

In Group 1, the pregnancy rate $(72.7 \%)$ and the incidence of twin pregnancies $(50 \%)$ recorded at slaughter or at calving showed that it is possible to produce identical twins by blastocyst bisection and unilateral transfer of 'half' blastocyst pairs to the uterine horn ipsilateral to the corpus luteum. These results are comparable with those obtained after bisection of Day-6-Day-7 morulae and unilateral transfer of 'half' morulae pairs $(64.2 \%$ pregnancy and $66.6 \%$ twinning rate; Ozil et al., 1982 ) but below those reported by Willadsen, Lehn-Jensen, Fehilly \& Newcomb (1981) after bilateral transfer of morulae bisected on Day 5 or 6 after 1 or 2 days of culture in ligated oviducts of anoestrous ewes (79\% pregnancy rate, $90.9 \%$ twinning rate). The present study shows the survival ability of embryos produced by bisecting blastocysts after the differentiation of the inner cell mass and the trophoblast.

In this study we decided to transfer two 'half' blastocysts into the ipsilateral horn for two reasons. Firstly, to examine the survival ability of each 'half' of the same blastocyst when transferred in the same conditions and into the same uterine environment. Because both 'halves' of 
PLATE 1
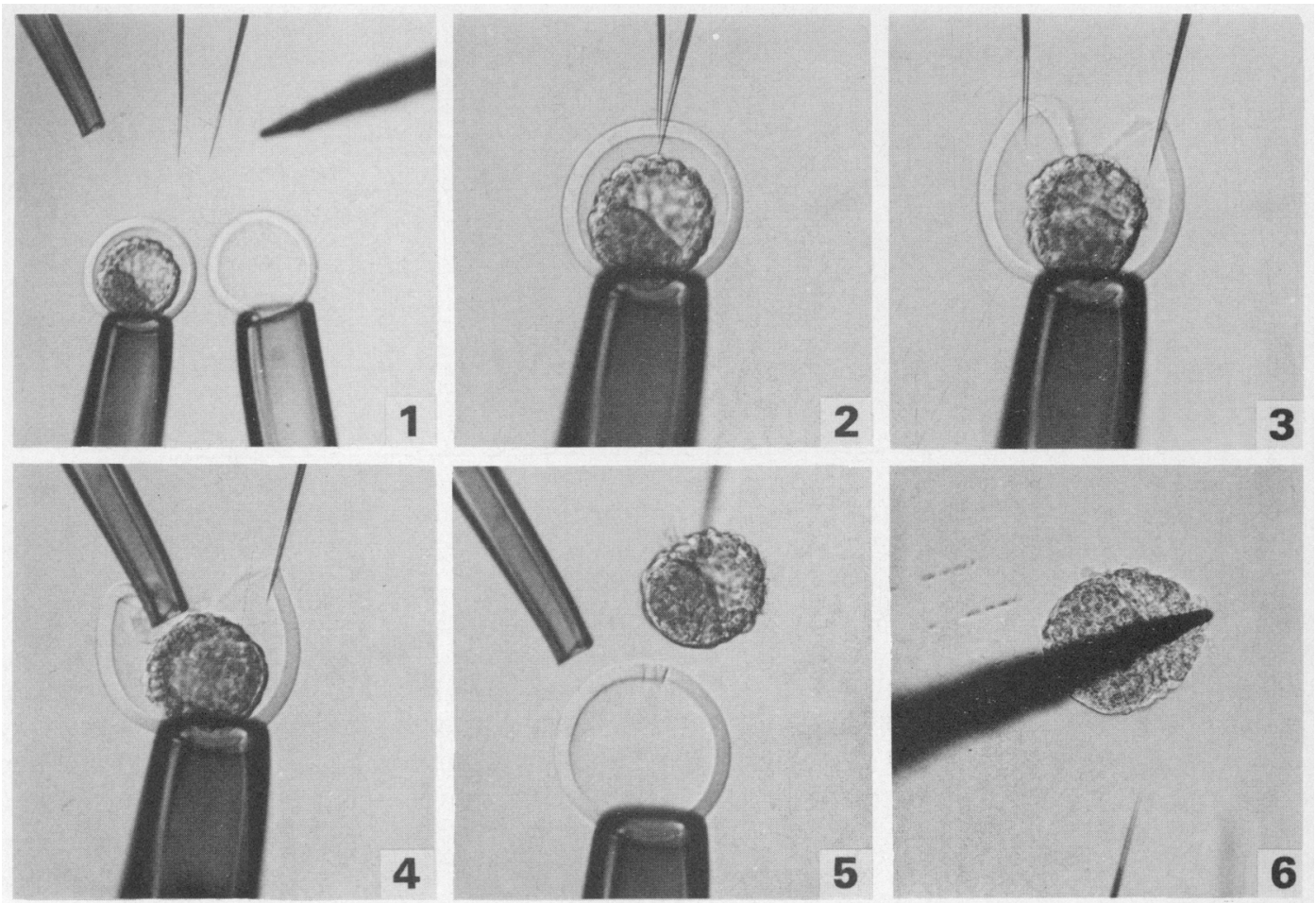

4
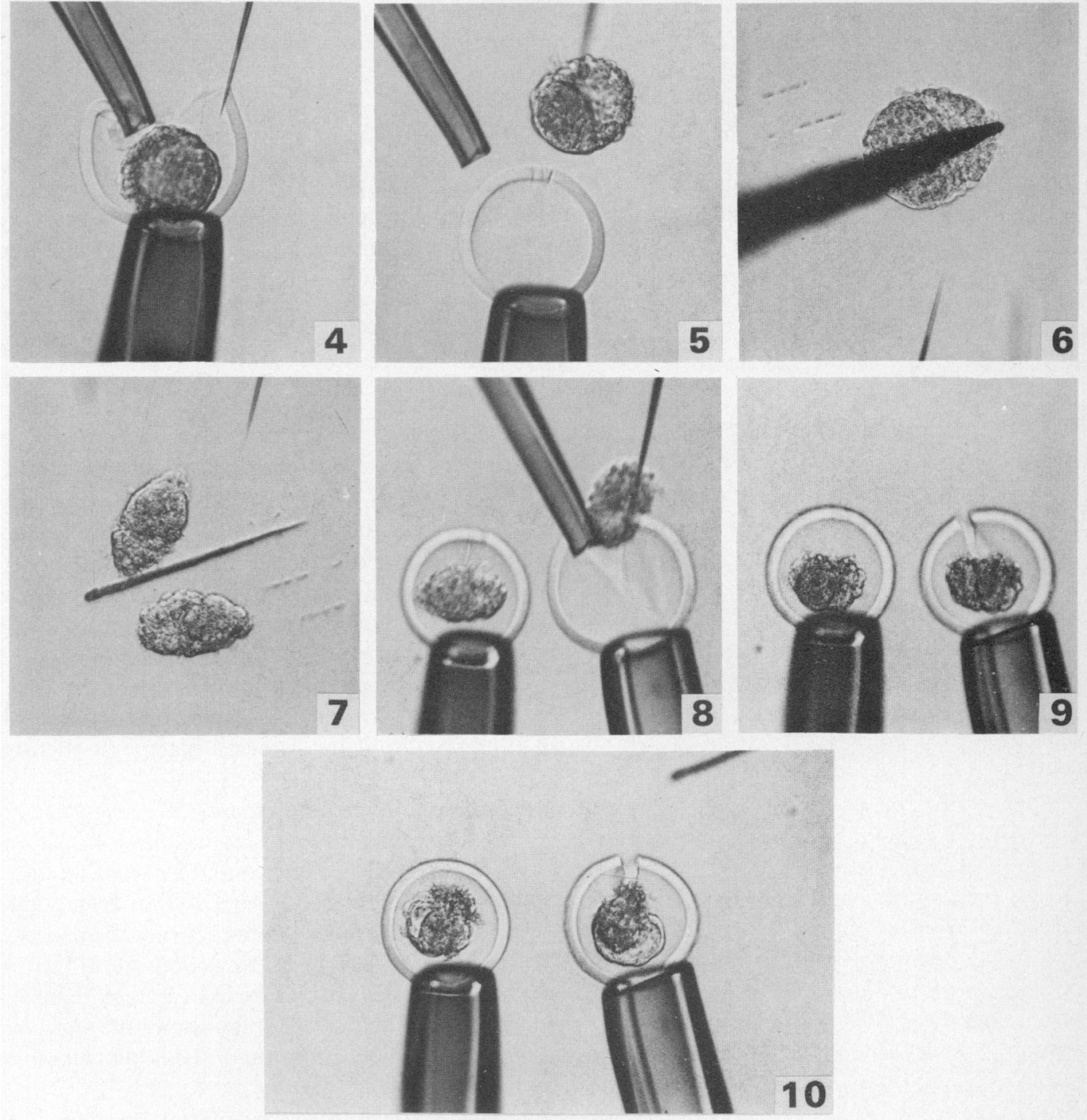
PLATE 2
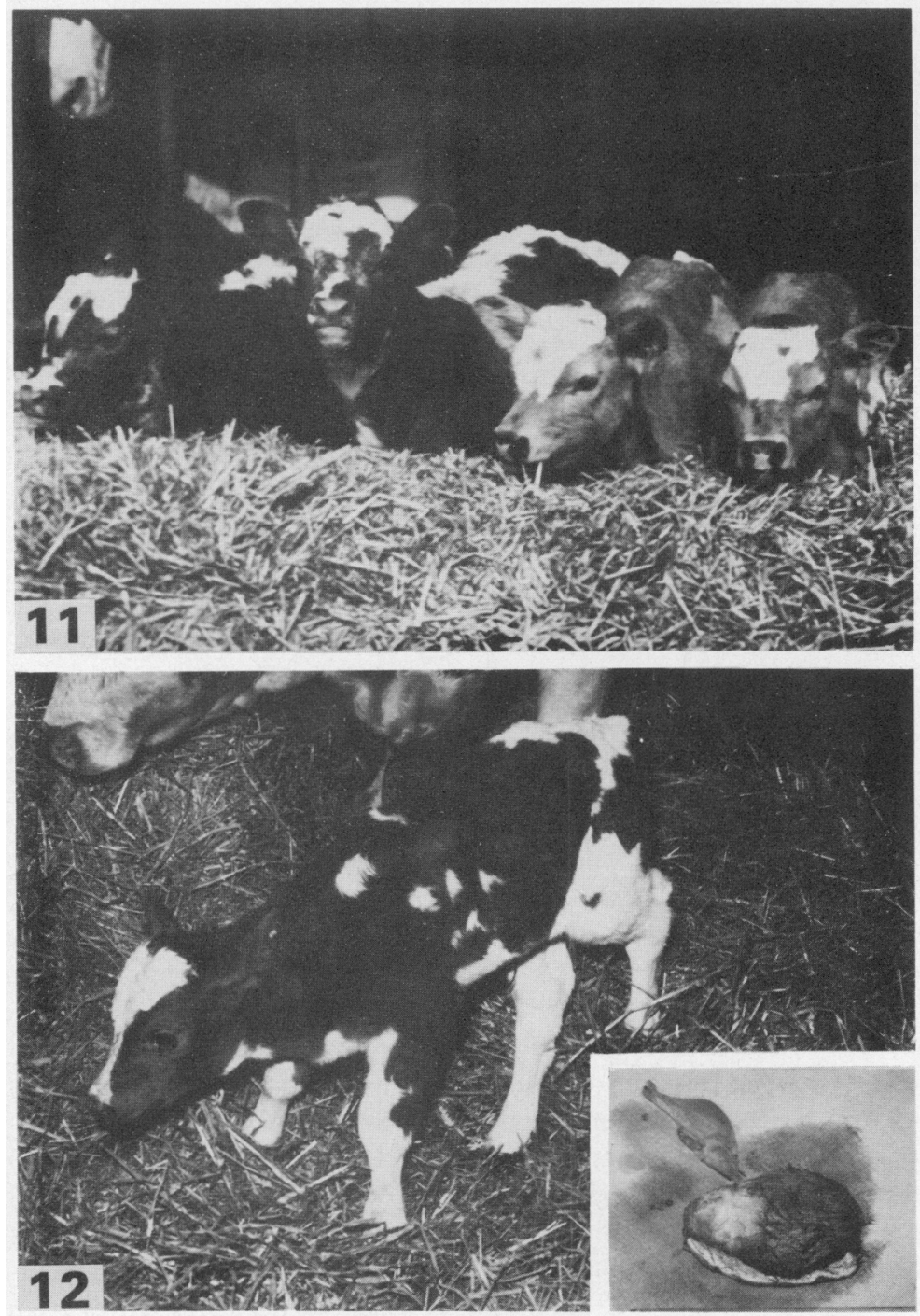

Fig. 11. Two sets of monozygotic twins born in September 1982, obtained after transfer of two bisected blastocysts.

Fig. 12. A normal call accompanied by a disorganized embryonic mass obtained after transfer of a pair of "half" blastocysts. The abnormal development of one "half" blastocyst may have been the result of an asymmetric division of the inner cell mass. 
the pair are in the same environment it may be assumed that the failure of development of one of them in a pregnant recipient is not due to the quality of the egg or the recipient but only to the intrinsic ability of each 'half' to survive after such bisection. In these conditions the survival rate was $12 / 16(75 \%)$. The conditions in which the fetal monster (acardiacus amorphus) appeared exclude the possibility of an error at the time of fetilization as suggested by Williams (1950) and supports the hypothesis of Eldrige (1980) that such a monster "could have resulted from an identical twin originating from some cells which had already become partially differentiated and therefore lacked the ability to develop into a normally organized foetus". At the blastocyst stage the cells have been irreversibly differentiated (Gardner, 1971) and therefore the normal development of 'half' blastocysts depends upon the proportion of inner cell mass and trophoblast cells in each 'half'. The second reason for unilateral transfer was to transfer the 'half' blastocyst pairs into the best physiological environment. It has been demonstrated (Heyman \& Renard, 1978) that when a single embryo was transferred non-surgically to the ipsilateral horn of a recipient the survival rate was greater $(51 \%)$ than when transferred non-surgically to the contralateral horn $(36 \%)$. In the present study the risk of losing one or both embryos after unilateral transfer of the embryos (Rowson, Lawson \& Moor, 1971) was avoided by transferring the 'half' blastocyst pairs by the cervical route to the base of the ipsilateral horn. Newcomb, Christie \& Rowson (1980) demonstrated that when two embryos were transferred to the ipsilateral horn, one to the tip and one to the base, $55 \%$ of twin pregnancies are bilateral. Such a transfer of 'half' blastocyst pairs of the ipsilateral horn allows the migration of one embryo to the contralateral horn and the normal development of twins.

In Group 2 the pregnancy rate at Day $42(45.4 \%)$, obtained after cervical transfer of a single 'half' blastocyst, showed that a single 'half' blastocyst is able to maintain the corpus luteum of the recipient and result in pregnancy. No difference in the pregnancy rate was recorded between the two groups $\left(\chi^{2}=1.65\right.$; d.f. $\left.1, P>0 \cdot 1\right)$. This result shows that it is possible to dissociate the transfer of each 'half' blastocyst and therefore to study the viability (Renard, Philippon \& Ménézo, 1980) or the karyotype of one 'half' while the other 'half' is transferred. The occurrence of 2 female fetuses of equal weight and crown-rump size could have been due to a spatial reorganization of the inner cell mass at the time of bisection, leading to 2 inner cell masses in this 'half' blastocyst or to a self division of the inner cell mass at a later stage, as has been shown by Corner (1955).

It is evident from these results that the bisection of a blastocyst has to be very precise to allow a normal development of each half and bisection outside the zona seems more practicable and precise than the technique developed by Williams, Elsden \& Seidel (1982) for early blastocysts on Day 7. This technique consisted of cutting through the zona pellucida and dividing the cell mass into two halves, one of which was then removed from that zona and placed into an evacuated zona.

The differences in the markings of the identical twins born (P1. 2, Fig. 11) has been noted by others (Willadsen, 1979). The confirmation of the monozygotic origin of these twins by the blood formulae shows that the distribution of the colour pigments in the skin is not entirely genetically controlled.

The present success rate of $51 \%$ for the number of live fetuses at Day 42 was at least equal to the number of blastocysts used for bisection and greater than that reported for the transfer of nonbisected embryos (Renard, Ozil \& Heyman, 1981). This technique is simpler than that described by Willadsen (1979), using early stage embryos. It allows the production of 6-8 'half' embryo pairs in $1 \mathrm{~h}$ in routine conditions and doubles the efficiency of cervical transfer in cows. The method could be simplified further if the 'half' blastocysts could survive without the protection of the zona pellucida.

These results show that it is possible to study directly the cryopreservation of 'half' blastocysts without any period of in-vivo culture in an intermediate recipient before deep freezing as was described by Lehn-Jensen \& Willadsen (1983). In preliminary experiments we have obtained several pregnancies and 1 calf after the transfer of 'half' blastocysts which were deep frozen by the method described by Renard et al. (1982) immediately after bisection. 
I thank Dr du Mesnil du Buisson for his constant encouragement; Dr. J. Testart for helpful suggestions and stimulating discussion; Mrs V. Garnier and P. Chesné for technical assistance; Mr R. Scandolo and C. Slagmulder for the photography; and Mrs M. E. Marmillod for her skilful typing of the manuscript.

\section{References}

Chupin, D. \& Procureur, R. (1983) Prediction of bovine ovarian response to PMSG by ultrasonic echography. Theriogenology 19, 119, Abstr.

Corner, G.W. (1955) The observed embryology of human single-ovum twins and other multiple births. $A m . J$. Obstet. Gynec. 70, 933-955.

Daniel, J.C., Jr (1963) Some kinetics of blastocyst formation as studied by the process of reconstitution. J. exp. Zool. 154, 231-237.

Dunn, H.O., Lein, D.H. \& Kenney, R.M. (1967) The cytological sex of a bovine anidian (Amorphus) twin monster. Cytogenetics 6, 412-419.

Eldrige, F.E. (1980) Chromosomes of Acardius Amorphus lamb. Proc. 4th Eur. Colloq. Cytogenet. Domest. Anim., 17-22.

Elsden, R.P., Nelson, L.D. \& Seidel, G.E. (1978) Super ovulating cows with follicle stimulating hormone and pregnant mare's serum gonadotrophin. Theriogeno$\log y$ 9, 1 , Abstr.

Gardner, R.L. (1971) Manipulations on the blastocyst. Adv. Biosci. 6, 279-296.

Grosclaude, F., Guérin, G. \& Houlier, G. (1979) The genetic map of the B system of cattle blood groups as observed in French breeds. Anim. Blood Grps biochem. Genet. 10, 199-218.

Heyman, Y. \& Renard, J.P. (1978) Production de jumeaux par transplantation d'embryons chez les bovins de races à viande. Annls Méd. Vét. 122, 157163.

Lehn-Jensen, H. \& Willadsen, S.M. (1983) Deep-freezing of cow 'half' and 'quarter' embryos. Theriogenology 19, 49-54.

Massip, A., Mulnard, D., Huygens, R., Hanzen, C., Van der Zwalmen, P. \& Ectors, F. (1981) Ultrastructure of the cow blastocyst. J. submicrosc. Cytol. 13, 31-40.

Ménézo, Y. (1976) Mise au point d'un milieu artificiel défini pour la survie et la maturation des gamètes et pour la culture de l'oeuf fécondé. C.r. hebd. Séanc. Acad. Sci., Paris D 282, 1967-1970.

Newcomb, R., Christie, W.B. \& Rowson, L.E.A. (1980) Fetal survival rate after the surgical transfer of two bovine embryos. J. Reprod. Fert. 59, 31-36.

Ozil, J.P. (1981) Duplication de l'embryon botin pour l'obtention de jumeaux monozygotes. D.E.S.S., Université P. et M. Curie, Paris VI, France.
Ozil, J.P., Heyman, Y. \& Cassou, R. (1980) Embryo recovery in young heifers and large old donor cows. Proc. 9th Int. Congr. Anim. Reprod. \& A.I., Madrid, pp. 581-584.

Ozil, J.P., Heyman, Y. \& Renard, J.P. (1982) Production of monozygotic twins by micromanipulation and cervical transfer in the cow. Vet. Rec. 110, 126-127.

Renard, J.P., Philippon, A. \& Ménézo Y. (1980) In-vitro uptake of glucose by bovine blastocysts. J. Reprod. Fert. 58, 161-164.

Renard, J.P., Ozil, J.P. \& Heyman, Y. (1981) Cervical transfer of deep frozen cattle embryos. Theriogeno$\log y 15,311-320$.

Renard, J.P., Heyman, Y. \& Ozil, J.P. (1982) Congélation de l'embryon bovin: une nouvelle méthode de décongélation pour le transfert d'embryons conditionnés une seule fois en paillettes. Annls Méd. Vét. 126, 23-32.

Rowson, L.E.A., Lawson, R.A.S. \& Moor, R.M. (1971) Production of twins in cattle by egg transfer. $J$. Reprod. Fert. 25, 261-268.

Whittingham, D.G. (1971) Survival of mouse embryos after freezing and thawing. Nature, Lond. 233, 125126.

Willadsen, S.M. (1979) A method for culture of micromanipulated sheep embryos and its use to produce monozygotic twins. Nature, Lond. 277, 298-300.

Willadsen, S.M. (1980) The viability of early cleavage stages containing half the normal number of blastomeres in the sheep. J. Reprod. Fert. 59, 357-362.

Willadsen, S.M. \& Polge, C. (1981) Attempts to produce monozygotic quadruplets in cattle by blastomere separation. Vet. Rec. 108, 211-213.

Willadsen, S.M., Lehn-Jensen, H., Fehilly, C.B. \& Newcomb, R. (1981) The production of monozygotic twins of preselected parentage by micromanipulation of non-surgically collected cow embryos. Theriogenology 15, 23-29.

Williams, T.J., Elsden, R.P. \& Seidel, G.E. (1982) Identical twin bovine pregnancies derived from bisected embryos. Theriogenology 47, 114, Abstr.

Williams, W.L. (1950) The Diseases of the Genital Organs of Domestic Animals; 3rd edn. William Plimpton, Worcester

Received 26 January 1983 